\title{
Glycogen storage disease due to glycogen debranching enzyme deficiency
}

INSERM

\section{Source}

INSERM. (1999). Orphanet: an online rare disease and orphan drug data base. Glycogen storage disease due to glycogen debranching enzyme deficiency. ORPHA:366

Glycogen debranching enzyme (GDE) deficiency, or glycogen storage disease type 3 (GSD 3), is a form of glycogen storage disease characterized by severe muscle weakness and hepatopathy. 